\title{
PENINGKATAN PENGELOLAAN ASRAMA UNTUK MENUNJANG KUALITAS PELAKSANAAN PENDIDIKAN DAN PELATIHAN
}

\author{
Ummi Faizah \\ Pusat Pengembangan dan Pemberdayaan Pendidik dan Tenaga Kependidikan Bidang Otomotif dan \\ Elektronika (PPPPTK BOE) Malang \\ Jl. Teluk Mandar Tromol Pos No.5, Arjosari, Blimbing, Kota Malang, Jawa Timur 65126 \\ Ifa.ajah@gmail.com
}

\begin{abstract}
The purpose of this research is to see the effectiveness of TQM implementation through ISO 9001: 2008 tools in preparation aspect of dorm room as supporting element in implementation of training implemented in PPPPTK BOE Malang. This study used descriptive qualitative method. The data is taken from the evaluation results of the implementation of the training in 2016. The results showed that the need for additional human resources both in quantity and quality, the addition of dormitory facilities, fund support and motivation from superiors in internalizing the implementation procedures that have been contained in ISO 9001: 2008.
\end{abstract}

Keywords: quality, dormitory, PPPPTK BOE Malang, ISO 9001: 2008.

\begin{abstract}
Abstrak : Tujuan penelitian ini untuk melihat keefektifan implementasi TQM melalui tools ISO 9001:2008 pada aspek penyiapan kamar asrama ysebagai unsur penunjang dalam pelaksanaan diklat yang dilaksanakan di PPPPTK BOE Malang. Penelitian ini menggunakan metode deskriptif kualitatif. Data diambil dari hasil evaluasi penyelenggaraan diklat tahun 2016. Hasil penelitian menunjukkan bahwa perlu adanya penambahan unsur SDM baik secara kuantitas maupun kualitas, penambahan fasilitas asrama, dukungan dana dan motivasi dari atasan dalam menginternalisasikan pelaksanaan prosedur yang telah tertuang dalam ISO 9001:2008.
\end{abstract}

Kata kunci: mutu, asrama, PPPPTK BOE Malang, ISO 9001:2008.

Kemajuan ilmu pengetahuan, teknologi, dan seni berdampak pada semua aspek kehidupan. Persaingan global terjadi dalam semua bidang baik yang memberikan layanan berupa produk maupun jasa, mereka berlomba-lomba memberikan yang terbaik pada para pelanggannya.

Pusat Pengembangan dan Pemberdayaan Pendidik dan Tenaga Kependidikan Bidang Otomotif dan Elektronika (PPPPTK BOE) Malang merupakan Unit Pelaksana Teknis (UPT) Direktorat Jenderal Guru dan Tenaga Kependidikan (Ditjen GTK). Berdasarkan Peraturan Menteri Pendidikan dan Kebudayaan Nomor 41 Tahun 2012 tentang Organisasi dan Tata
Kerja, PPPPTK mempunyai tugas melaksanakan pengembangan dan pemberdayaan pendidik dan tenaga kependidikan sesuai dengan bidangnya. Salah satu wujud implementasi dari tugas pokok dan fungsinya adalah dengan dilaksanakannya berbagai pendidikan dan pelatihan (diklat) baik yang diperuntukkan bagi guru-guru Sekolah Menengah Kejuruan (SMK) maupun hasil kerja sama dengan dunia industri. Sebagai sebuah organisasi yang bergerak dibidang jasa, maka sudah menjadi sebuah konsekwensi untuk senantiasa berusaha memberikan layanan prima agar dapat mencapai kepuasan pelanggannya, baik pelanggan internal maupun eksternal. 
Salah satu upaya yang telah dilakukan oleh PPPPTK BOE Malang adalah dengan menerapkan Sistem Manajemen Mutu ISO 9001:2008, yaitu suatu standar internasional untuk sistem manajemen Mutu/kualitas. ISO 9001:2008 menetapkan persyaratan-persyaratan dan rekomendasi untuk desain dan penilaian dari suatu sistem manajemen mutu. ISO 9001:2008 bukan merupakan standar produk, karena tidak menyatakan persyaratan - persyaratan yang harus dipenuhi oleh sebuah produk (barang atau jasa). ISO 9001:2008 hanya merupakan standar sistem manajemen kualitas. Namun, bagaimanapun juga diharapkan bahwa produk/jasa yang dihasilkan dari suatu sistem manajemen kualitas internasional, akan berkualitas baik (standar).

Sehingga dapat disimpulkan bahwa Quality Management Systems (ISO 9001:2008) adalah merupakan prosedur terdokumentasi dan praktekpraktek standar untuk manajemen sistem, yang bertujuan menjamin kesesuaian dari suatu proses dan produk (barang atau jasa) terhadap kebutuhan atau persyaratan tertentu, dimana kebutuhan atau persyaratan tertentu tersebut ditentukan atau dispesifikasikan oleh pelanggan dan organisasi.

Beberapa organisasi memakaifilosofi dengan nama sendiri, misalnya, Total Quality Control, Total Quality service, Continuos Improvement, strategic Quality Initiatives, Service Quality (Sallis, 2012:75). Melalui penamaan tersebut, diharapkan berpengaruh terhadap budaya kualitas di dalam organisasi yang bersangkutan. TQM berkaitan dengan penciptaan budaya kualitas yang bertujuan agar karyawan dan staf dapat memuaskan konsumen sekaligus didukung oleh struktur organisasi mereka dalam melakukan hal yang dimaksud. TQM merupakan suatu pendekatan dalam menjalankan usaha yang mencoba untuk memaksimumkan daya saing organisasi melalui perbaikan terus-menerus atas produk, jasa, manusia, proses, dan lingkungannya (Tjiptono dan Diana, 2003:4).

Pendidikan dan pelatihan (diklat) merupakan salah satu bentuk layanan yang diberikan oleh PPPPTK BOE Malang yang telah tersistem dalam ISO 9001:2008. Untuk menjaga kualitas diklat, maka evaluasi penyelenggaraan diklat selalu dilaksanakan diakhir kegiatan. Evaluasi dilakukan dengan menggunakan instrumen. Hasil evaluasi akan ditindaklanjuti untuk memperbaiki kualitas diklat. Instrumen evaluasi pe- nyelenggaraan diklat berisi tentang program, layanan administrasi, kegiatan pembelajaran, dan fasilitas penunjang. Berdasarkan hasil evaluasi penyelenggaraan diklat tahun 2016, program mendapatkan skor 3,4 (sangat baik), layanan administrasi mendapatkan skor 3,2 (sangat baik), kegiatan pembelajaran mendapatkan skor 3,3 (sangat baik), dan fasilitas penunjang mendapatkan skor 3,4 (sangat baik).

Unsur fasilitas penunjang terdiri atas penyiapan kamar dengan skor 3,2 (sangat baik), penyiapan konsumsi dengan skor 3,6 (sangat baik) dan penyiapan fasilitas lain dengan skor 3,5 (sangat baik). Dari hasil evaluasi tersebut bisa diketahui bahwa semua unsur memiliki nilai sangat baik, namun demikian masih ada beberapa keluhan pelanggan terkait penyiapan kamar. Keluhan tersebut antara lain adalah: (1) kurang bersihnya kamar mandi asrama, (2) kamar tidak dibersihkan selama kegiatan, (3) kurangnya fasilitas meja dalam kamar, (4) asrama tidak terjangkau wifi. Asrama merupakan unsur penunjang dalam proses pelaksanaan diklat. Walaupun sebagai unsur penunjang, namun demikian keberadaannya tidak bisa diabaikan begitu saja, karena peserta tidak akan nyaman beristirahat bila kualitas asrama tidak bagus. Hal ini akan berdampak pada tingkat keterserapan materi oleh peserta dan berhasil tidaknya diklat yang telah dilaksanakan.

\section{METODE}

Penelitian ini bertujuan untuk menganalisis hasil implementasi ISO 9001:2008, khususnya pada layanan penyiapan kamar atau asrama yang merupakan bagian dari penerapan TQM dalam Sistem Manajemen Mutu di PPPPTK BOE Malang. Penelitian ini menggunakan pendekatan kualitatif dengan rancangan penelitian deskriptif. Kriteria yang digunakan untuk menentukan keberhasilan implementasi standart prosedur ISO tersebut antara lain adalah:(1) adanya peningkatan kualitas dan kuantitas SDM yang bertugas dalam layanan penyiapan kamar asrama sebagai salah satu unsur penunjang keterlaksaan diklat yang dilaksanakan di lingkungan PPPPTK BOE Malang, (2) adanya peningkatan fasilitas kamar asrama dengan memfokuskan pada kebutuhan dan harapan pelanggan (peserta diklat), (3) adanya dukungan anggaran untuk peningkatan 
kualitas fisik kamar asrama, dan (4) adanya motivasi dari atasan dalam hal implementasi prosedur sebagaimana yang tertuang dalam SMM ISO 9001:2008 PPPPTK BOE Malang.

Data penelitian ini dikumpulkan dengan teknik wawancara dan studi dokumentasi. Adapun data yang diambil adalah data yang terkait dengan pelayanan kamar asrama, yang terdiri atas: (1) data hasil evaluasi penyelenggaraan kegiatan tahun 2016, (2) data kualitas dan kuantitas sumber daya manusia pengelola asrama, dan (3) anggaran yang digunakan sebagai biaya perawatan asrama. Teknik analisis deskriptif kualitatif digunakan untuk mengungkap gambaran keberhasilanimplementasi ISO 9001:2008 dalam layanan penyiapan kamar asrama. Proses analisis data berdasarkan Ulfatin (2015:257) meliputi: (1) pengumpulan data, (2) reduksi data, yaitu penelaahan dalam memilah data yang diterima disesuaikan kondisi lapangan yang ada, (3) display data, yaitu hasil dari reduksi yang disusun secara terstruktur, dan (4) verifiksi data, yaitu mengkroscek kecocokan makna data yang diperoleh dari lapangan untuk mencapai kesimpulan yang kuat.

\section{HASIL}

Hasil-hasil penelitian ini dapat dideskripsikan berdasarkan urutan pencapaian tujuan penelitian. Berdasarkan tujuan yang sudah ditentukan, ada tiga (3) kriteria yang diungkap dalam penelitian ini. Pertama, SDM yang bertugas dalam layanan penyiapan kamar asrama baik secara kuantitas maupun secara kualitas. Hasil analisis data ditunjukkan sebagai berikut. Jumlah kamar asrama yang tersedia adalah 126 kamar dengan jumlah petugas kebersihan sembilan (9) orang dan dua (2) orang koordinator. Secara kuantitas rerata perbandingan antara jumlah kamar dengan tenaga kebersihan adalah 1:15. Secara kualitas, tingkat pendidikan petugas kebersihan kamar adalah SMA, dari segi usia rata-rata berusia empat puluh tiga (43) tahun dengan status tujuh (7) orang PNS dan dua (2) orang KKWT (Karyawan Kontrak Waktu Tertentu).

Kedua, fasilitas pendukung asrama belum lengkap. Akses internet di asrama yang sangat kurang mendukung dan kurang tersedianya meja kursi di dalam kamar sangat menyulitkan peserta diklat dalam menyelesaikan tugas-tugas yang diberikan oleh narasumber ketika proses diklat berlangsung. PPPPTK BOE Malang adalah lembaga diklat yang notabene peserta diklat berasal dari unsur pendidik SMK. Materi diklat seringkali menggunakan fasilitas internet, selain itu juga tidak jarang ada tugas yang harus dikerjakan oleh peserta ketika waktu pelaksanaan diklat, sehingga kebutuhan fasilitas penunjang berupa akses internet dan meja kursi belajar dalam kamar asrama sangat mutlak diperlukan oleh peserta diklat.

Ketiga, kurangnya dukungan anggaran untuk peningkatan kualitas fisik kamar asrama serta panjangnya proses pencairan dana sehingga menghambat proses pengadaan bahan yang digunakan untuk perawatan kamar asrama.

Keempat, diperlukan motivasi dari atasan dalam hal ini Kepala Bagian Umum dan Kasubbag Tata Usaha dan Rumah Tangga untuk dapat menginternalisasikan budaya kualitas supervisor dan petugas kebersihan kamar asrama, melalui pemanfaatan beberapa form yang telah ditetapkan dalam standart mutu ISO 9001:2008 sehingga proses perbaikan secara berkelanjutan diharapkan akan bisa terus berjalan.

\section{PEMBAHASAN}

PPPPTK BOE Malang pada prinsipnya telah menjalankan Total Quality Management melalui Sistem Manajemen Mutu ISO 9001:2008, namun belum optimal. Berdasarkan hasil analisis, beberapa kendala yang dihadapi yaitu: (1) secara kuantitas, jumlah SDM petugas asrama dirasa kurang mengingat luasnya area kerja yang dikerjakan; (2) dari sisi usia, petugas asrama PPPPTK BOE Malang berada dalam rentang usia 35 hingga 47 tahun; (3) dari sisi pendidikan, petugas asrama adalah lulusan SMA, sementara itu bila dibandingkan dengan roomboy hotel minimal lulusan SMK jurusan perhotelan yang secara skill mereka telah terlatih. Hal ini jelas menimbulkan ketimpangan secara kualitas SDM. Sebagai aternatif pemecahan masalah yang bisa diambil adalah dengan menambah jumlah petugas asrama dengan kualifikasi dan kompetensi yang dibutuhkan sesuai rasio yang diperlukan, sehingga permasalahan asrama yang berkaitan dengan petugas bisa segera teratasi sehingga bisa meningkatkan kualitas pelayanan asrama.

Permasalahan berikutnya (4) kurangnya fasilitas asrama dan kurangnya dukungan 
anggaran bisa diatasi dengan dilakukannya penganggaran pada tahun berikutnya, sehingga tujuan perbaikan dengan fokus pada pelanggan dan perbaikan secara berkelanjutan bisa senantiasa dilakukan. Adapun untuk permasalahan (5) dukungan motivasi dari atasan petugas asrama sangat diperlukan, mengingat manajemen mutu terpadu akan dapat terlaksana dengan sangat baik bila mendapat dukungan dan melibatkan peranan dari seluruh lini di instansi tersebut sehingga budaya mutu akan dapat tercipta ditiap unit kerja. Formulir yang digunakan sebagai media kontrol kebersihan dan perawatan fasilitas asrama yang selama ini kurang berjalan, perlu dioptimalkan kembali oleh koordinator asrama. Sehingga progress kebersihan dan perawatan asrama akan dapat terjaga. Menurut Fattah (2013: 29) pengawasan/kotrol pada sistem penjaminan mutu dilakukan untuk mengukur pencapaian standar acuan mutu pendidikan. Sementara itu, hasil penelitian Mawardi, dkk. (2014: 300304) tentang Implementasi Quality Assurance System dalam Pembelajaran di SMKN 3 Malang, mengungkapkan bahwa pengawasan dilakukan guna mengetahui kemajuan pelaksanaan pembelajaran dan pencapaian atas programprogram lain di MAN 3 Malang.

Perbaikan secara terus menerus melalui sistem PDCA (plan, do, chech, action) melekat pada sistem evaluasi atas kinerja per individu maupun per bagian terhadap permasalahan yang teridentifikasi melalui instrumen evaluasi penyelenggaraan diklat merupakan kerangka implementasi continous improvement. Penyiapan asrama sebagai unsur penunjang dalam pelaksanaan diklat akan berjalan optimal bila PDCA dijalankan seefektif mungkin. Gaspersz (2003: 271) berpendapat, bahwa pelaksanaan proses yang konsisten merupaka kunci untuk peningkatan terus-menerus.

Sebagai lembaga yang memiliki core business dibidang pendidikan dan pelatihan, kualitas atau mutu memegang peranan penting untuk dapat unggul dalam persaingan. Hal ini sejalan dengan hasil penelitian Purwanti, dkk. (2015: 354-553) yang melakukan penelitian tentang implementasi sistem manajemen mutu ISO 9001:2008 dalam meningkatkan kualitas lulusan di SMK Negeri 1 Bangil, bahwa pentingnya Sistem Manajemen Mutu ISO 9001:2008 dalam lembaga pendidikan membawa dampak terhadap semua guru dan karyawan dalam memberikan pelayanan yang lebih baik. Melalui pelayanan yang lebih baik dapat meningkatkan kualitas lulusannya.

Pentingnya dibangun iklim kerja dan budaya kualitas disetiap unit kerja merupakan salah satu kunci berhasilnya implementasi TQM dalam sebuah instansi. Namun demikian, penciptaan budaya kualitas membutuhkan proses yang panjang, bertahap dan berkelanjutan serta membutuhkan sumber daya yang memadai, baik dari sisi man, money dan material. Mulyono (2008: 315) berpendapat, bahwa proses penerapan budaya mutu melalui serangkaian tahapan diantaranya yaitu adanya komitmen manajemen, menetapkan timpengembang, serta pelatihan kesadaran atau pemahaman terhadap mutu. Sementara itu Suharsaputra (2010: 234) berpendapat salah satu karakteristik TQM yaitu dengan memperbaiki proses secara berkesinambungan.

Penerapan prinsip-prinsip TQM pada SMM yang mencakup pemfokusan pada pelanggan, perbaikan pada proses, dan pelibatan anggota dalam berbagai kegiatan telah berjalan. Pemfokusan kegiatan pada pelanggan (peserta diklat) sudah dilakukan, tetapi belum optimal, sebagaimana diungkapkan oleh Peters \& Waterman (1992), bahwa TQM menekankan kualitas pelanggan adalah raja sebagai pendekatan. Sementara itu Sallis (2012: 26) berpendapat implementasi TQM berkaitan dengan penciptaan budaya kualitas dengan menempatkan tujuan karyawan dan staf untuk memuaskan konsumen. Jika prinsip-prinsip tersebut dilakukan secara konsisten dalam jangka panjang, dapat menghasilkan layanan jasa pendidikan yang baik. Hal ini sesuai dengan prinsip yang harus diperhatikan, yaitu selalu ada perbaikan dalam setiap proses ketika mengimplementasikan TQM, apalagi sebagai institusi yang telah menjalankan ISO 9001:2008. Supriyanto \& Sunandar (2011: 273) berpendapat, bahwa dalam menerapkan konsep TQM terdapat tiga prinsip, yaitu (1) pemfokusan terhadap pengguna, (2) peningkatan kualitas proses, dan (3) pelibatan semua komponen pendidikan.

\section{KESIMPULAN DAN SARAN}

\section{Kesimpulan}

Berdasarkan hasil penelitian yang telah dilakukan, dapat ditarik sebuah kesimpulan, 
bahwa PPPPTK BOE Malang pada prinsipnya telah menjalankan Total Quality Management melalui Sistem Manajemen Mutu ISO 9001:2008 namun ada beberapa kendala yang dihadapi yaitu: (1) secara kuantitas, jumlah SDM petugas asrama dirasa kurang mengingat luasnya area kerja yang dikerjakan; (2) dari sisi usia, petugas asrama PPPPTK BOE Malang berada dalam rentang usia 35 hingga 47 tahun; (3) dari sisi pendidikan, petugas asrama adalah lulusan SMA, sementara itu bila dibandingkan dengan roomboy hotel minimal lulusan SMK jurusan perhotelan yang secara skill mereka telah terlatih, (4) kurangnya fasilitas asrama dan kurangnya dukungan anggaran, dan (4) kurang dukungan motivasi dari atasan petugas asrama.

\section{Saran}

Berdasarkan hasil penelitian, saran yang bisa diberikan kepada pimpinan PPPPTK BOE Malang yaitu; (1) perlu adanya peningkatan SDM khususnya petugas asrama baik dari segi kualitas maupun kuantitas, (2) pengadaan dan penambahan fasilitas asrama guna menunjang keterlaksaan diklat; dan (3) perlunya dukungan dana dan motivasi dari atasan dalam upaya internalisasi budaya mutu petugas asrama.

\section{DAFTAR RUJUKAN}

Gaspersz, V. 2003. Totyal Quality Management. Jakarta: PT. Gramedia Pustaka Utama.

Mawardi, R. S., Soetopo, H., dan Supriyanto. A. 2014. Implementasi Quality Assurance System dalam Pembelajaran. Manajemen Pendidikan, Volume 24, Nomor 4, September 2014. P. 300-304.

Mulyono. 2008. Manajemen Administrasi \& Organisasi Pendidikan. Jogjakarta: Ar-Ruzz Media.

Peters, T. and Waterman, R. 1992. In Search of Excellent. New York: Harper and Row.

Purwanti, E., Wiyono, B. B., dan Sunandar, A. Implementasi Sistem Manajemen Mutu ISO 9001:2008 dalam Meningkatkan Kualitas Lulusan. Manajemen Pendidikan, Volume 24 Nomor 6, September 2015, p.547-553.

Sallis, E. 2012. Total Quality Management in Education. Jogjakarta: IRCiSoD.

Suharsaputra, U. 2010. Administrasi Pendidikan. Bandung: PT. Refika Aditama.

Supriyanto, A. dan Sunandar, A. 2011. Model Implementasi Konsep TQM dalam Pembelajaran. Manajemen Pendidikan, Volume 23, Nomor 3, Maret 2011 p.264-277.

Tjiptono, F. \& Diana, A. 2003. Total Quality Management. Yogyakarta: Andi Offset.

Ulfatin, N. 2015. Metode Penelitian Kualitatif di Bidang Pendidikan: Teori dan Aplikasinya. Malang: Media Nusa Creative. 